\title{
Diagnostic performance of thorax CT in mildly symptomatic COVID-19 patients: The importance of atypical CT findings
}

\author{
(1) Serkan Emre Eroglu, ${ }^{1}$ (1) Abdullah Algin, ${ }^{1}$ (i) Safiye Sanem Dereli Bulut, ${ }^{2}$ (i) Zakir Sakci, ${ }^{2}$ \\ (D) Mehtap Aydin, ${ }^{3}$ (D) Gokhan Aksel, ${ }^{1}$ (D) Ibrahim Altunok, ${ }^{1}$ (D) Hatice Seyma Akca, ${ }^{1}$ (D) Yasar Bukte $^{2}$ \\ ${ }^{1}$ Department of Emergency Medicine, Health Sciences University, Umraniye Research and Training Hospital, Istanbul, Turkey \\ ${ }^{2}$ Department of Radiology, Health Sciences University, Umraniye Research and Training Hospital, Istanbul, Turkey \\ ${ }^{3}$ Department of Infectious Diseases and Clinical Microbiology, Health Sciences University, Umraniye Research and Training Hospital, Istanbul, \\ Turkey
}

\begin{abstract}
OBJECTIVE: Computed tomography of the thorax (Thorax CT) is frequently used to diagnose viral pneumonia in moderate to severe COVID-19 patients, but its diagnostic performance in mildly symptomatic COVID-19 patients is still unclear. Assessing the diagnostic performance of thorax CT in mildly symptomatic COVID-19 patients was the purpose of our study.

METHODS: Mildly symptomatic and clinically stable, suspected COVID-19 patients scanned with Thorax CTs between March 11, 2020, and April 13, 2020, were included in this study. The sensitivity, specificity, positive and negative likelihood ratios, positive and negative predictive values, and the respective accuracies were calculated for diagnostic purposes.

RESULTS: Among the 1119 patients enrolled in our study, abnormal thorax CT scans were 527 out of which $363 / 527$ (68.9\%) had typical CT features for COVID-19. According to analysis of typical COVID findings, sensitivity, specificity, positive predictive values, negative predictive value, and the accuracy of Thorax CTs with were 51.45\%, 86.07\%, 78.24\%, 64.55\%, and $68.99 \%$, respectively. When typical CT findings and atypical CT findings were combined for the statistical analysis, the sensitivity, specificity, and accuracy observed $68.84 \%, 74 \%$, and $71.49 \%$.
\end{abstract}

CONCLUSION: Diagnosing pneumonia can be challenging in mildly symptomatic COVID-19 patients since the Reverse Transcription Polymerase Chain Reaction test results, when compared with symptoms are not always evident. According to our study, thorax CT sensitivity was higher when atypical COVID-19 CT findings were included compared to those with typical COVID-19 CT findings alone. Our study which included the largest number of patients among all other similar studies indicates that not only typical but also atypical CT findings should be considered for an accured diagnosis of COVID-19 pneumonia.

Keywords: Accuracy; mild COVID-19; thorax CT.

Cite this article as: Eroglu SE, Algin A, Dereli Bulut SS, Sakci Z, Aydin M, Aksel G, et al. Diagnostic performance of thorax CT in mildly symptomatic COVID-19 patients: The importance of atypical CT findings. North Clin Istanb 2021;8(5):425-434.

$\mathrm{C}$ omputed tomography (CT) has played an important role in the detection of many pathologies since its invention in 1972. It can be said that this role has become essential with the coronavirus disease-19 (COVID-19) pandemic that has affected the world in recent months, over 75 million cases and 1.6 million deaths have been reported as a result of this pandemic all over the world [1]. The fast spread of this disease affected the general socio-economic life and overwhelmed the health systems around the world.

Received: December 30, 2020 Accepted: January 23, 2021 Online: October 19, 2021

Correspondence: Serkan Emre EROGLU, MD. Saglik Bilimleri Universitesi, Umraniye Egitim ve Arastirma Hastanesi, Acil Tip Anabilim Dali, Istanbul, Turkey.

Tel: +90 5323010866 e-mail: drseroglu@gmail.com

(c) Copyright 2021 by Istanbul Provincial Directorate of Health - Available online at www.northclinist.com 
It is known that COVID-19 caused by "severe acute respiratory syndrome coronavirus (SARS-CoV-2)" particularly affects the respiratory tract and may progresses into the acute respiratory distress syndrome. The reverse transcription polymerase chain reaction (RT-PCR) test is the main tool for the diagnosis of this disease worldwide. RT-PCR is often performed to all patients with COVID-19 symptoms. Whether their clinical condition is mild, moderate or severe, false negative results may often be encountered due to the practitioner's technique and the accuracy of the test kit. Long test completion durations are also a major burden in front of a quick diagnosis $[2,3]$.

These disadvantages prove to be crucial in mild COVID-19 patients. The medical management of suspected COVID-19 patients with moderate to severe symptoms requires immediate action thus ensuring that they remain isolated. While patients with mild COVID-19 symptoms waiting for their test results, may continue to spread the disease. Most of the patients whom were clinically stable and were accepted as mild COVID-19 cases undergoing thorax CTs had faster detections of lung pathologies compared to the same patients waiting for RT-PCR test results for the confirmation of COVID-19. This proves that the use of thorax CTs can play a beneficial role in the early management of mild COVID-19 pneumonia [4].

This paper aims to assess the diagnostic performance of thorax CTs in screening suspected COVID-19 patients with clinically stable and mildly symptoms.

\section{MATERIALS AND METHODS}

\section{Study Design and Participants}

This retrospective study was conducted in the University of Health Sciences Umraniye Training and Research Hospital's Emergency service ward (ESW), Istanbul/ Turkey. This ward has approximately 580,000 annual patient visits.

From March the 11, 2020, to April the 13, 2020, clinically stable patients whom underwent thorax CTs in the ESW and had simultaneous RT-PCR test for suspected COVID-19 infection were included into this study.

The Institutional Review Board approved the study on April 14, 2020 (University of Health Sciences Umraniye Training and Research Hospital, Protocol Number: B.10.1.TKH.4.34.H.GP.0.01/98), Due to its retrospective design, the informed consent was not obtained from patients who participated in our study.

\section{Highlight key points}

- This study aims to assess the diagnostic performance of thorax CTs in screening suspected COVID-19 patients with mild and clinically stable symptoms

- This study indicates that GGO, other subtypes, or LSS do not make a statistically significant difference in 30-day mortality.

- In RT-PCR positive patients, the 30-day mortality rate was $5.2 \%$ for patients with atypical CT abnormalities and $1.1 \%$ for those with typical CT abnormalities (Chi-square test, $p=0.023$ ).

- A further precious result of our study is that the sensitivity of the group with all CT abnormalities is higher than the group in which only typical CT findings were obtained (68.84\% vs. $51.45 \%)$.

- According to our study results, the presence of typical COVID-19 CT findings being the primary criteria for hospitalization is not sufficient for the detection of the risk of mortalities. Hence, the other CT abnormalities should also be considered for the management of COVID-19.

Consecutive patients who met the following inclusion criteria were included in this study: (a) Age $\geq 18$ years; (b) having mild symptoms associated with COVID-19; (c) having stable vital findings; and (d) having been tested with RT-PCR and simultaneously going through thorax CT screening at admission to the ESW.

The patients detected during the data analysis from our hospital information system who were hemodynamically unstable, clinically unstable or had no mild symptoms, were excluded from this study.

\section{Definition of "Mild Symptoms" and "Clinically Stable Patients"}

The decision of the clinical stability and the presence of mild symptoms were based on the evaluations of the patients during the admission of patients at the triage.

During the emergency triage admission, the presence of no difficulty in breathing or shortness of breath history that required urgent intervention, no chest pain or pressure, and other complaints that never been thought life threating, were considered as mild symptoms.

Clinical stability was defined as achievement of normal vital signs plus normal mental status, ability to eat, mobility, and not require immediate lifesaving interventions. Among the patients who meet these conditions, an oxygen saturation level below $93 \%$, or heart rate $>100$ bpm, or a systolic blood pressure level $<100 \mathrm{mmHg}$, or breathing more than 20 breaths/min, were considered abnormal, and excluded from the study. 


\begin{tabular}{|c|c|c|c|c|}
\hline & Group with $\mathrm{CT}$ findings & Group without CT findings & Total population & $\mathrm{p}$ \\
\hline Age (years) median (range) & $46(18-95)$ & $34(18-87)$ & $40(18-95)$ & $<0.001$ \\
\hline Under 50 years old, $\mathrm{n}(\%)$ & 59.2 & 84.3 & $811(72.5)$ & \\
\hline Over 50 years old, $\mathrm{n}(\%)$ & $215(40.8)$ & $93(15.7$ & $308(27.5)$ & \\
\hline \multicolumn{5}{|l|}{ Gender (n) } \\
\hline Male, n (\%) & 56 & 59.3 & $646(57.7)$ & 0.263 \\
\hline Female, n (\%) & 44 & 40.7 & $473(42.3)$ & \\
\hline Comorbidity number & $0(0-5)$ & $0(0-4)$ & $<1(0-5)$ & $<0.001$ \\
\hline Comorbid disease presence & & & & $<0.001$ \\
\hline No, n (\%) & 73.1 & $521(88$ & 81 & \\
\hline Yes, n (\%) & 26.9 & $71(12$ & 19 & \\
\hline \multicolumn{5}{|l|}{ Comorbidities $(+n /-n)$} \\
\hline COPD & $20 / 507$ & $13 / 579$ & $33 / 1086$ & 0.114 \\
\hline HTN & $81 / 446$ & $39 / 553$ & $120 / 999$ & $<0.001$ \\
\hline DM & $67 / 460$ & $31 / 561$ & $98 / 1021$ & $<0.001$ \\
\hline CAD & $23 / 504$ & $7 / 585$ & $30 / 1089$ & 0.001 \\
\hline $\mathrm{CHF}$ & $8 / 519$ & $2 / 590$ & $10 / 1109$ & 0.036 \\
\hline CKD & $6 / 521$ & $3 / 589$ & $9 / 1110$ & 0.238 \\
\hline Active malignancy & $15 / 512$ & $2 / 590$ & $17 / 1102$ & 0.001 \\
\hline Immunodeficiency state & $2 / 525$ & $1 / 591$ & $3 / 1116$ & 0.496 \\
\hline Smoking status, n (\%) & & & & 0.503 \\
\hline Smoker & 2.1 & 2.7 & 2.4 & \\
\hline Non smoker & 97.9 & 97.3 & 97.6 & \\
\hline \multicolumn{5}{|c|}{ Frequency of symptoms, $\mathrm{n}(\%)$} \\
\hline Fever & 38.7 & 31.1 & $388(34.7)$ & 0.007 \\
\hline Cough & 66.8 & 64 & $731(65.3)$ & 0.331 \\
\hline Sputum & 3.8 & 3.5 & $41(3.7)$ & 0.826 \\
\hline Shortness of breath & 28.5 & 35 & $357(31.9)$ & 0.020 \\
\hline Other complaints & 15 & 15.5 & $171(15.3)$ & 0.799 \\
\hline
\end{tabular}

CT: Computed tomography; COPD: Chronic obstructive pulmonary disease; HTN: Hypertension; DM: Diabetes mellitus; CAD: Coronary artery disease; CHF: Chronic heart failure; CKD: Chronic kidney disease.

\section{Data Collection and CT Image Analysis}

The data of the patients' included in our study were taken out from our hospital's medical records. The RTPCR tests of the patients were performed with real time kits (SARS-CoV-2 detection kit; Coyote Bioscience Co., Ltd). The thorax CT scans were screened with a GE OPTİMA 660128 slice CT scanner.

In the CT scans initial findings including consolidation, linear opacities, the presence of ground glass opacities (GGO), pleural effusions, thoracic lymphadenopathies, and lung severity scores were evaluated respectively.
The definition of abnormal findings was used for all findings that were found to be different from the thorax CT examination of an adult healthy person. In addition to this, the evaluations of typical and atypical COVID-19 CT findings were based on the current literature $[2,5-8]$. The bilateral and multifocal GGO, Crazy paving appearance, consolidation (multifocal foci with irregular contours, generally located peripherally in the lower lobe), peribronchovascular thickening, air bronchogram, halo sign, reverse halo sign, air bubble sign, subpleural, and parenchymal bands in the lungs were considered as typical thorax CT findings of COVID-19 pneumonia. Central in- 


\begin{tabular}{|c|c|c|c|c|}
\hline & $\begin{array}{l}\text { Group with } \\
\text { CT findings }\end{array}$ & $\begin{array}{l}\text { Group without } \\
\text { CT findings }\end{array}$ & $\begin{array}{c}\text { Total } \\
\text { population }\end{array}$ & $\mathrm{p}$ \\
\hline \multicolumn{5}{|l|}{ RT-PCR test, n (\%) } \\
\hline Test $(+)$ & 72.1 & 29.1 & $552(49.3)$ & $<0.001$ \\
\hline Test (-) & 27.9 & 70.9 & $567(50.7)$ & \\
\hline \multicolumn{5}{|l|}{ COVID-19 finding presence in CT } \\
\hline No, $\mathrm{n}(\%)$ & & 592 & $592(52.9)$ & \\
\hline \multicolumn{5}{|l|}{ Yes, n (\%) } \\
\hline Atypical & 31.1 & & $164(14.7)$ & \\
\hline Typical & 68.9 & & $363(32.4)$ & \\
\hline \multicolumn{5}{|l|}{ Thorax CT features, n (\%) } \\
\hline Ground-glass opacification & 93.2 & & $491(43.9)$ & $<0.001$ \\
\hline Consolidation & 28.7 & & $151(13.5)$ & \\
\hline Pulmonary nodules & 14 & & $74(6.6)$ & \\
\hline Pleural effusion & 5.7 & & $30(2.7)$ & \\
\hline Thoracic lymphadenopathy & 0.4 & & $2(0.2)$ & \\
\hline Fibrosis/emphysema & 24.9 & & $131(11.7)$ & \\
\hline Other abnormalities & 4.9 & & $26(2.3)$ & \\
\hline The number of ground glass consolidated lobes median (range) & $2(0-5)$ & & & \\
\hline LSS median (range) & $3(0-20)$ & & & \\
\hline Intubation status, n (\%) & $8(1.5)$ & $2(0.3)$ & $10(0.9)$ & 0.031 \\
\hline \multicolumn{5}{|l|}{ First 24 -h outcome, $\mathrm{n}(\%)$} \\
\hline Emergency discharge & 49 & 94.3 & $816(72.9)$ & $<0.001$ \\
\hline Hospitalization & 50.3 & 5.6 & $298(26.6)$ & \\
\hline Admission to the ICU death & 0.8 & 0.2 & $5(0.4)$ & \\
\hline 30-day mortality, n (\%) & 1.9 & 0.3 & $12(1.1)$ & 0.011 \\
\hline
\end{tabular}

RTPCR: Reverse transcriptase polymerase chain reaction; LSS: Lung severity score; ICU: Intensive care unit.

volvement isolated upper lobe involvement, solitary involvement, peribronchovascular involvement, lobar consolidation, tree-in-bud pattern, nodules, pleural effusion, pericardial effusion, subpleural sparing, white lung (diffuse infiltration - involving the lung) were considered as atypical thorax CT findings of COVID-19 pneumonia. The anatomical structure of the lungs was evaluated according to their Lung Severity Scores (LSSs). In this evaluation, each lung lobe (5 lobes) was evaluated separately and scored according to the involvement scale (the respective values are 0 for $0 \%$ involvement; 1 for $1-25 \%$ lobe involvement; 2 for $26-50 \%$ lobe involvement; 3 for $51-75 \%$ lobe involvement; and 4 for $76-100 \%$ lobe involvement). The total score of 5 lobes was accepted as the patient's LSS (range, 0-20).
Two radiologists, each with 5 years of experience, were blinded to clinical and laboratory data and reviewed the CT images. Their concentual decisions were applied. In the case of a disagreement, another radiologist with 10 years of experience reviewed the images for a final decision.

\section{Statistical Analysis}

Statistical analysis was performed with SPSS 26 (IBM Corp. Released 2019. IBM SPSS Statistics for Windows, Version 26.0. Armonk, NY: IBM Corp.). Categorical variables were described as frequency (percentage), continuous variables with normal distribution were described with mean (SD), and the others as median, and interquartile range (IQR) values. Median and range were used for expressing continuous variables which have no 
TABLE 2A. Baseline characteristics according to thorax CT results in RT-PCR positive patients

\begin{tabular}{|c|c|c|c|c|c|}
\hline & $\begin{array}{l}\text { Atypical CT finding } \\
(n=96,17.4 \%)\end{array}$ & $\begin{array}{l}\text { Typical CT finding } \\
(\mathrm{n}=284,51.4 \%)\end{array}$ & $\begin{array}{l}\text { No CT finding } \\
(n=172,31.2 \%)\end{array}$ & $\begin{array}{l}\text { Total } \\
(n=552)\end{array}$ & $\mathrm{p}$ \\
\hline Age (years) & $51(20-94)$ & $47(18-89)$ & $36(18-87)$ & $44(18-94)$ & $<0.001$ \\
\hline Under 50-years-old $(n / \%)$ & 47.9 & 58.5 & 77.3 & $345(62.5)$ & \\
\hline Over 50-years-old (n/\%) & 52.1 & 41.5 & 22.7 & $207(37.5)$ & \\
\hline Gender & $\%$ & $\%$ & $\%$ & $\mathrm{n} /(\%)$ & \\
\hline Male & 60.4 & 51.8 & 56.4 & $302(54.7)$ & 0.294 \\
\hline Female & 39.6 & 48.2 & 43.6 & $250(45.3)$ & \\
\hline Comorbidity number & $0(0-4)$ & $0(0-5)$ & $0(0-3)$ & $0(0-5)$ & 0.001 \\
\hline Comorbid disease presence & $\%$ & $\%$ & $\%$ & $\mathrm{n} /(\%)$ & \\
\hline No & 65.6 & 71.8 & 84.3 & $412(74.6)$ & 0.001 \\
\hline Yes & 34.4 & 28.2 & 15.7 & $140(25.4)$ & \\
\hline \multicolumn{6}{|l|}{ Comorbidities $(+n /-n)$} \\
\hline COPD & $3 / 93$ & $11 / 273$ & $6 / 166$ & $20 / 532$ & 0.938 \\
\hline HTN & $20 / 76$ & $46 / 238$ & $11 / 161$ & $77 / 475$ & 0.001 \\
\hline DM & $13 / 83$ & $43 / 241$ & $10 / 162$ & $66 / 486$ & 0.010 \\
\hline CAD & $7 / 89$ & $12 / 272$ & $3 / 169$ & $22 / 530$ & 0.081 \\
\hline $\mathrm{CHF}$ & $4 / 92$ & $4 / 280$ & $2 / 170$ & $10 / 542$ & 0.161 \\
\hline CKD & $2 / 94$ & $2 / 282$ & $2 / 170$ & $6 / 546$ & 0.527 \\
\hline Active malignancy & $4 / 92$ & $6 / 278$ & $1 / 171$ & $11 / 541$ & 0.129 \\
\hline Immunodeficiency state & $1 / 95$ & $1 / 283$ & $1 / 171$ & $3 / 549$ & 0.727 \\
\hline Smoking status & $\%$ & $\%$ & $\%$ & $\mathrm{n} /(\%)$ & \\
\hline Smoker & 2.1 & 0.7 & 1.2 & $6(1.1)$ & 0.527 \\
\hline Non smoker & 97.9 & 99.3 & 98.8 & $546(98.9)$ & \\
\hline Frequency of symptoms & $\%$ & $\%$ & $\%$ & $\mathrm{n} /(\%)$ & \\
\hline Fever & 40.6 & 41.9 & 39.5 & $226(40.9)$ & 0.881 \\
\hline Cough & 61.5 & 70.1 & 64 & $368(66.7)$ & 0.200 \\
\hline Sputum & 4.2 & 4.2 & 2.3 & $20(3.6)$ & 0.548 \\
\hline Shortness of breath & 30.2 & 23.2 & 25.6 & $139(25.2)$ & 0.393 \\
\hline Other complaints & 17.7 & 13.7 & 18 & $87(15.8)$ & 0.404 \\
\hline
\end{tabular}

CT: Computed tomography; RTPCR: Reverse transcriptase polymerase chain reaction; COPD: Chronic obstructive pulmonary disease; HTN: Hypertension; DM: Diabetes mellitus; CAD: Coronary artery disease; CHF: Chronic heart failure; CKD: Chronic kidney disease.

normal distribution. Normal distribution was tested by Kolmogorov-Smirnow and Shapiro-Wilk test. MannWhitney U-test was used to test the differences of quantitative variables between two groups. While Chi-square test or Fisher's exact test were used for categorical variables, Kruskal-Wallis test was used for continuous variables. Sensitivity, specificity, positive likelihood ratio and negative likelihood ratio, positive predictive value, negative predictive value, and accuracy were used for assessing as diagnostic accuracy. The RT-PCR result was taken as reference for this purpose. $\mathrm{P} \leq 0.05$ was admitted statistically significant.

\section{RESULTS}

Characteristics of Study Subjects and Demography

Between March 11, 2020, and April 13, 2020, a total of 1119 patients met the criteria to be included in our study. Of these, 646 were men and 473 were women. The patients had a median age of 40 years (IQR: 29, 52; range 18-95 years).

Within the total of the patents 61 (40 men and 21 women) had combined symptoms of fever, cough and shortness of breath. In addition, 171 patients had other complaints (Table 1a, b). 
TABLE 2B. Baseline characteristics according to thorax CT results in RT-PCR positive patients

$\begin{array}{ccccc}\text { Atypical CT finding } & \text { Typical CT finding } & \text { No CT finding } & \text { Total } & p \\ (n=96,17.4 \%) & (n=284,51.4 \%) & (n=172,31.2 \%) & (n=552) & \\ \% & \% & \% & n(\%)\end{array}$

Thorax CT features

Ground-glass opacification

Consolidation

Pulmonary nodules

Pleural effusion

Thoracic lymphadenopathy

Fibrosis/emphysema

Other abnormalities

The number of ground glass consolidated lobes

LSS

Intubation status ( $\mathrm{n} / \%)$

First 24-h outcome (n/\%)

Emergency discharge

Hospitalization

Admission to the ICU death

30-day mortality ( $\mathrm{n} / \%)$

Ground-glass opacification

Consolidation

Pulmonary nodules

Pleural effusion

Thoracic lymphadenopathy

Fibrosis/emphysema

Other abnormalities

The number of ground glass consolidated lobes LSS
Thorax CT features (n/\%)

\begin{tabular}{|c|c|c|c|c|}
\hline 81.3 & 98.9 & & 359 (65) & $<0.001$ \\
\hline 31.3 & 28.2 & & $110(19.9)$ & $<0.001$ \\
\hline 15.6 & 10.6 & & $45(8.2)$ & $<0.001$ \\
\hline 12.5 & 3.5 & & $22(4)$ & $<0.001$ \\
\hline 1 & 0.4 & & $2(0.4)$ & 0.396 \\
\hline 33.3 & 21.5 & & $93(16.8)$ & $<0.001$ \\
\hline 7.3 & 2.8 & & $15(2.7)$ & 0.002 \\
\hline $1(0-5)$ & $4(1-5)$ & & $2(0-5)$ & $<0.001$ \\
\hline $2(0-10)$ & $5(1-17)$ & & $2(0-17)$ & $<0.001$ \\
\hline 3.1 & 1.1 & 1.2 & $8(1.4)$ & 0.318 \\
\hline 47.9 & 41.9 & 82 & $306(55.4)$ & $<0.001$ \\
\hline 52.1 & 157.4 & 17.4 & $243(44)$ & \\
\hline 0 & 0.7 & 0.6 & $3(0.5)$ & \\
\hline 5.2 & 1.1 & 1.2 & $10(1.8)$ & 0.023 \\
\hline 81.3 & 98.9 & & 359 (65) & $<0.001$ \\
\hline 31.3 & 28.2 & & $110(19.9)$ & $<0.001$ \\
\hline 15.6 & 10.6 & & $45(8.2)$ & $<0.001$ \\
\hline 12.5 & 3.5 & & $22(4)$ & $<0.001$ \\
\hline 1 & 0.4 & & $2(0.4)$ & 0.396 \\
\hline 33.3 & 21.5 & & $93(16.8)$ & $<0.001$ \\
\hline 7.3 & 2.8 & & $15(2.7)$ & 0.002 \\
\hline $1(0-5)$ & $4(1-5)$ & & $2(0-5)$ & $<0.001$ \\
\hline $2(0-10)$ & $5(1-17)$ & & $2(0-17)$ & $<0.001$ \\
\hline
\end{tabular}

CT: Computed tomography; RTPCR: Reverse transcriptase polymerase chain reaction; COPD: Chronic obstructive pulmonary disease; HTN: Hypertension; DM: Diabetes mellitus; CAD: Coronary artery disease; CHF: Chronic heart failure; CKD: Chronic kidney disease; LSS: Lung severity score; ICU: Intensive care unit.
552 (49.3\%) of the patients had positive RT-PCR test results.

The median age of the patients having abnormal findings on CT scans was higher than those patients without abnormal findings on their respective $\mathrm{CT}$ scans (46 [IQR: 36, 59; range 18-95] and 34 [IQR: 27, 45; range 18-87], respectively) (Mann-Whitney U-test, $\mathrm{p}<0.001$ ).

It was found that comorbidities such as diabetes mellitus (DM), hypertension (HTN), coronary artery disease (CAD), chronic heart failure, chronic kidney disease, and active malignancy were more common in patients with abnormal CT scans compared to those with normal CT scans. HTN was the most common comorbidity $(n=120,10.7 \%)$, followed by DM $(n=98$, $8.8 \%)$. This result was also found to be statistically significant (Table 1a). In addition to this, while there was a statistically significant association between RT-PCR results and the presence of HTN or DM (Chi-square test, $\mathrm{p}=0.041$ and $\mathrm{p}=0.025)$, no significant association was found between CAD, Active malignancy, COPD or immune deficiency (Chi-square test, $\mathrm{p}=0.251 ; \mathrm{p}=0.634$; $\mathrm{p}=0.830 ; \mathrm{p}=378)$.

Upon admission to the ESW, $243 / 552$ patients (44\%) were hospitalized, a further three out of them were transferred to the intensive care unit. 


\begin{tabular}{|c|c|c|c|c|}
\hline & $\begin{array}{c}\text { Emergency discharge } \\
(n=165,43.42 \%) \\
\%\end{array}$ & $\begin{array}{c}\text { Hospitalization } \\
\text { (Service+ICU) } \\
\%\end{array}$ & $\begin{array}{c}\text { Total } \\
(\mathrm{n}=380) \\
\mathrm{n}(\%)\end{array}$ & $\mathrm{p}$ \\
\hline \multicolumn{5}{|l|}{ Thorax CT features } \\
\hline Ground-glass opacification & 51 & 82.5 & $359(65)$ & $<0.001$ \\
\hline Consolidation & 15 & 26 & $110(19.9)$ & 0.001 \\
\hline Pulmonary nodules & 7.2 & 9.3 & $45(8.2)$ & 0.357 \\
\hline Pleural effusion & 2.9 & 5.3 & $22(4)$ & 0.162 \\
\hline Thoracic lymphadenopathy & 0.3 & 0.4 & $2(0.4)$ & 0.877 \\
\hline Fibrosis/emphysema & 14.1 & 20.6 & $93(16.8)$ & 0.051 \\
\hline Other abnormalities & 2.3 & 3.3 & $15(2.7)$ & 0.489 \\
\hline The number of ground glass consolidated lobes & $1(0-5)$ & $3(0-5)$ & $2(0-5)$ & $<0.001$ \\
\hline LSS & $1(0-17)$ & $4(0-17)$ & $2(0-17)$ & $<0.001$ \\
\hline
\end{tabular}

CT: Computed tomography; RT-PCR: Reverse transcription polymerase chain reaction; ICU: Intensive care unit; LSS: Lung severity score.

According to the "first 24-h outcome" results, none of the patients had died, but $12 / 552$ patients had died by the $30^{\text {th }}$ day after their admission. $10 / 12$ of them had abnormal findings on their initial CTs (Table 1b). There was a statistically significant difference between the presence of CT findings and 30-day mortality (Fisher's Exact test, $\mathrm{p}=0.011$ ).

\section{Thorax CT Evaluation}

Among all patients, 527/1119 (47.1\%; 295 men and 232 women) had thorax CT abnormalities at their admission. 363 out of 527 patients $(68.9 \%)$ had typical and the remaining 164 patients had atypical CT features (Table 1b).

284 out of 363 patients with typical CT features had positive RT-PCR test results. In addition, 96 out of 164 patients with atypical CT features had positive RT-PCR test results. Typical CT findings were found in 80 out of 140 patients with comorbidities (Table 2, b). It was found out that the CT findings of the patients included in the study differed significantly according to the RTPCR test results (Chi-square test, $\mathrm{p}<0.001)$.

491 out of $527(93.2 \%)$ patients had ground glass appearance, 151 out of $527(28.7 \%)$ patients had consolidation (Table $1 \mathrm{~b}$ ), and 135/527 (25.6\%) patients had ground glass appearance together with consolidation. The number of lobes with ground glass or consolidation appearance was higher in the RT-PCR positive group compared to the RT-PCR negative group (median num- ber of 2 [IQR: 0, 4; range 0-5] and 0 [IQR: 0 , range 0 ; $0-5]$ respectively) (Mann-Whitney U-test, $\mathrm{p}<0.001$ ).

Within these 527 patients, the median LSS was 3 (IQR: 1,5 ; range $0-20$ ).

In terms of outcome including the first $24 \mathrm{~h}$, we found out that a larger percentage of patients with typical CT findings $(67.07 \%)$ were hospitalized compared to the ones without CT findings (Kruskal-Wallis test, $\mathrm{p}<0.001$ ).

We have observed a significant relationship between hospitalization rates and the presence of GGO, or consolidation, or increased score in LSS in RT-PCR positive patients (Table 3). In the same group of patients, the 30 -day mortality rate was $5.2 \%$ for patients with atypical CT abnormalities and $1.1 \%$ for those with typical CT abnormalities (Chi-square test, $p=0.023$ ). The death rate was $1.2 \%$ in patients with no CT findings (Table $2 \mathrm{a}, \mathrm{b}$ ). There was no statistically significant relationship on the 30-day mortality and the CT findings or the subtypes or the LSS (Table 4).

\section{Diagnostic Performance of Thorax CTs}

According to the analysis of diagnostic performance of thorax CTs, including both typical and atypical CT findings, thorax CTs had a $68.84 \%$ (95\% Confidence interval [CI], 64.79-72.68) sensitivity, 74\% (95\% CI, 70.2677.64) specificity, and $71.49 \%$ (95\% CI, 68.75-74.12) accuracy. 
TABLE 4. Association between CT findings and 30-Day mortality in RT-PCR positive patients

\begin{tabular}{lcccc} 
& $\begin{array}{c}\text { Survivors } \\
\%\end{array}$ & $\begin{array}{c}\text { Deaths } \\
\%\end{array}$ & $\begin{array}{c}\text { Total } \\
\mathrm{n}(\%)\end{array}$ & $\mathrm{p}$ \\
& & & & \\
\hline Thorax CT features & 64.8 & 80 & $359(65)$ & 0.506 \\
$\quad$ Ground-glass opacification & 19.7 & 30 & $110(19.9)$ & 0.426 \\
$\quad$ Consolidation & 7.9 & 20 & $45(8.2)$ & 0.193 \\
$\quad$ Pulmonary nodules & 3.9 & 10 & $22(4)$ & 0.336 \\
$\quad$ Pleural effusion & 0.4 & & $2(0.4)$ & 0.070 \\
$\quad$ Thoracic lymphadenopathy & 16.4 & 40 & $93(16.8)$ & $15(2.7)$ \\
$\quad$ Fibrosis/emphysema & 2.8 & 4 & & 0.346 \\
$\quad$ Other abnormalities & 4 & 6 & & 0.142 \\
The number of ground glass consolidated lobes & 5 & & &
\end{tabular}

CT: Computed tomography; RT-PCR: Reverse transcription polymerase chain reaction; LSS: Lung severity score.

TABLE 5. Diagnostic performance of thorax CT, according to included/excluded atypic COVID-19 CT findings

\begin{tabular}{lcr} 
& With atypic CT findings & With only typic CT findings \\
\hline Sensitivity (\%) & $68.84(\mathrm{CI}, 64.79-72.68)$ & $51.45(\mathrm{CI}, 47.19-55.69)$ \\
Specificity (\%) & $74(\mathrm{CI}, 70.26-77.64)$ & $86.07(\mathrm{CI}, 82.94-88.81)$ \\
Positive likelihood ratio (\%) & $2.66(\mathrm{CI}, 2.29-3.09)$ & $3.69(\mathrm{CI}, 2.96-4.6)$ \\
Negative likelihood ratio (\%) & $0.42(\mathrm{CI}, 0.37-0.48)$ & $0.56(\mathrm{CI}, 0.51-0.61)$ \\
Pozitive predictive value (\%) & $72.11(\mathrm{CI}, 68.99-75.02)$ & $78.24(\mathrm{CI}, 74.26-81.75)$ \\
Negative predictive value (\%) & $70.95(\mathrm{CI}, 68.13-73.61)$ & $64.55(\mathrm{CI}, 62.42-66.63)$ \\
Accuracy (\%) & $71.49(\mathrm{CI}, 68.75-74.12)$ & $68.99(\mathrm{CI}, 66.19-71.69)$ \\
Prevelance (\%) & $49.33(\mathrm{CI}, 46.36-52.3)$ &
\end{tabular}

CT: Computed tomography; CI: Confidence interval (95\%).

Thorax CTs (only typical findings for COVID-19) had 51.45\% (95\% CI, 47.19-55.69) sensitivity, 86.07\% (95\% CI, 82.94-88.81) specificity, and 68.99\% (95\% CI, 66.19-71.69) accuracy in the diagnose of COVID-19 patients. The positive and negative likelihood ratios for the same group of patients were 3.69 and 0.56 , respectively (Table 5).

\section{DISCUSSION}

When we have searched the relative literature, we found out that our study has the largest number of involved patients (1119) compared to other similar studies [9-13]. Our study also includes data on the diagnostic performance of CTs and important demographic data.
Most cases presented in other related papers report that patients had median ages ranging from 44.6 to 63 years. The patients were predominantly male, their most common complaint was fever and their most common comorbid was HTN [14-20]. Likewise, we also found that the majority of the cases were male, had similar age range, and the most common comorbidity was HTN in our study. In fact, the most common complaint was not fever but cough. Similarly, as in many studies, GGO was also found to be the most common CT finding $[6,14,21]$.

Our study shows that the detection of typical COVID findings such as GGO is among the necessary criteria for the diagnosis of COVID-19 and for hospitalization. Our study also shows that GGO, other 
subtypes or LSS do not make a statistically significant difference in 30-day mortality.

The relationship between the detection of abnormalities in CTs and the respective 30-day mortality rate is one of the most important results of our study. The abnormal CT features subtypes were found not to be related to mortality.

The presence of typical COVID-19 CT findings being the primary criteria for hospitalization is not sufficient for the detection of the risk of mortalities. Hence, the other CT abnormalities should also be considered for the management of COVID-19. This would be a crucial step in the management of the clinically stable (mild) COVID-19 patients and will help in taking the wright decisions in the course of treatment.

Based on the literature, thorax CTs have relatively high sensitivities and varying specificities in the diagnosis of COVID-19. The thorax CT sensitivity for the diagnosis of COVID-19 is ranging from $77 \%$ to $98 \%$ and the relative specificity is varies from $37 \%$ to $96 \%$ [2, 9-11, $22]$. The sensitivity and specificity rates in our study have been lower than in these studies. The involvement of a high number of patients with the inclusion of clinically stable patients proves to be the main factor for the importance of our study. A further precious result of our study is that the sensitivity of the group with all CT abnormalities is higher than the group in which only typical CT findings were obtained (68.84\% vs. $51.45 \%)$.

Therefore, in the management of these patients with recent CT abnormalities, it will be correct to consider COVID-19 pneumonia until RT-PCR test results are available, or other differential diagnoses have been ruled out.

A limitation of this study is its retrospective design from a single center.

\section{Conclusion}

According to our study, thorax CT sensitivity was higher when atypical COVID-19 CT findings were included compared to those with typical COVID-19 CT findings alone. This result suggests that the absence of typical COVID findings should not rule out COVID-19. The fact that patients with atypical COVID-19 CT findings have a higher 30-day mortality rate than others also supports this argument.

Our study showed that any new CT abnormalities, whether typical or atypical, should be considered in favor of COVID-19 pneumonia in a patient presenting with mild COVID-19 symptoms.
Ethics Committee Approval: The Health Sciences University, Umraniye Research and Training Hospital Clinical Research Ethics Committee granted approval for this study (date: 14.04.2020, number: B.10.1.TKH.4.34.H.GP.0.01/98).

Conflict of Interest: No conflict of interest was declared by the authors.

Financial Disclosure: The authors declared that this study has received no financial support.

Authorship Contributions: Concept - SEE, AA; Design - SEE, AA, $\mathrm{GA}$; Supervision - SEE, MA, YB; Data collection and/or processing SEE, ZS, SSDB, IA, HSA; Analysis and/or interpretation - SEE, AA, GA; Literature review - SEE, MA, AA, GA; Writing - SEE, AA, SSDB, GA; Critical review - SEE, MA, AA, GA.

\section{REFERENCES}

1. World Health Organization. COVID-19 Weekly Epidemiological Uptade. Available at: https://www.who.int/publications/m/item/weeklyepidemiological-update---22-december-2020. Accessed Dec 23, 2020.

2. Jalaber C, Lapotre T, Morcet-Delattre T, Ribet F, Jouneau S, Lederlin M. Chest CT in COVID-19 pneumonia: A review of current knowledge. Diagn Interv Imaging 2020;101:431-7. [CrossRef]

3. Huang EP, Sung CW, Chen CH, Fan CY, Lai PC, Huang YT. Can computed tomography be a primary tool for COVID-19 detection? Evidence appraisal through meta-analysis. Crit Care 2020;24:193. [CrossRef]

4. Li P, Chen L, Liu Z, Pan J, Zhou D, Wang H, et al. Clinical features and short-term outcomes of elderly patients with COVID-19. Int J Infect Dis 2020;97:245-50. [CrossRef]

5. Bernheim A, Mei X, Huang M, Yang Y, Fayad ZA, Zhang N, et al. Chest CT findings in coronavirus disease-19 (COVID-19): Relationship to duration of infection. Radiology 2020;295:200463. [CrossRef]

6. Hu Q, Guan H, Sun Z, Huang L, Chen C, Ai T, et al. Early CT features and temporal lung changes in COVID-19 pneumonia in Wuhan, China. Eur J Radiol 2020;128:109017. [CrossRef]

7. Ceylan N, Savas R. Radiological findings of COVID-19 pneumonia. Eurasian J Pulmonol 2020;22:19-24. [CrossRef]

8. Pan F, Ye T, Sun P, Gui S, Liang B, Li L, et al. Time course of lung changes at chest CT during recovery from coronavirus disease 2019 (COVID-19). Radiology 2020;295:715-21. [CrossRef]

9. Böger B, Fachi MM, Vilhena RO, Cobre AF, Tonin FS, Pontarolo R. Systematic review with meta-analysis of the accuracy of diagnostic tests for COVID-19. Am J Infect Control 2021;49:21-9. [CrossRef]

10. He JL, Luo L, Luo ZD, Lyu JX, Ng MY, Shen XP, et al. Diagnostic performance between CT and initial real-time RT-PCR for clinically suspected 2019 coronavirus disease (COVID-19) patients outside Wuhan, China. Respir Med 2020;168:105980. [CrossRef]

11. Fang Y, Zhang H, Xie J, Lin M, Ying L, Pang P, et al. Sensitivity of Chest CT for COVID-19: Comparison to RT-PCR. Radiology 2020;296:E115-7. [CrossRef]

12. Krdzalic J, de Jaegere TMH, Kwee RM. Diagnostic performance of chest CT in screening patients with suspected COVID-19 infection in a Western population. Br J Radiol 2020;93:20200643. [CrossRef]

13. Himoto Y, Sakata A, Kirita M, Hiroi T, Kobayashi KI, Kubo K, et al. Diagnostic performance of chest CT to differentiate COVID-19 pneumonia in non-high-epidemic area in Japan. Jpn J Radiol 2020;38:4006. [CrossRef]

14. Li K, Fang Y, Li W, Pan C, Qin P, Zhong Y, et al. CT image visual 
quantitative evaluation and clinical classification of coronavirus disease (COVID-19). Eur Radiol 2020;30:4407-16. [CrossRef]

15. Richardson S, Hirsch JS, Narasimhan M, Crawford JM, McGinn T, Davidson KW; et al. Presenting characteristics, comorbidities, and outcomes among 5700 patients hospitalized with COVID-19 in the New York City area. JAMA 2020;323:2052-9. [CrossRef]

16. Cui N, Zou X, Xu L. Preliminary CT findings of coronavirus disease 2019 (COVID-19). Clin Imaging 2020;65:124-32. [CrossRef]

17. Aksel G, İslam MM, Algıı A, Eroğlu SE, Yaşar GB, Ademoğlu E, et al. Early predictors of mortality for moderate to severely ill patients with Covid-19. Am J Emerg Med 2020 Aug 28 [Epub ahead of print], doi: 10.1016/j.ajem.2020.08.076. [CrossRef]

18. Siordia JA Jr. Epidemiology and clinical features of COVID-19: A review of current literature. J Clin Virol 2020;127:104357. [CrossRef]
19. Shah SJ, Barish PN, Prasad PA, Kistler A, Neff N, Kamm J, et al. Clinical features, diagnostics, and outcomes of patients presenting with acute respiratory illness: A retrospective cohort study of patients with and without COVID-19. EClinicalMedicine 2020;27:100518. [CrossRef]

20. Khan G, Sheek-Hussein M, Al Suwaidi AR, Idris K, Abu-Zidan FM. Novel coronavirus pandemic: A global health threat. Turk J Emerg Med 2020;20:55-62. Erratum in: Turk J Emerg Med 2020;20:156. [CrossRef]

21. Shang Y, Xu C, Jiang F, Huang R, Li Y, Zhou Y, et al. Clinical characteristics and changes of chest CT features in 307 patients with common COVID-19 pneumonia infected SARS-CoV-2: A multicenter study in Jiangsu, China. Int J Infect Dis 2020;96:157-62. [CrossRef]

22. Kim H, Hong H, Yoon SH. Diagnostic performance of CT and reverse transcriptase polymerase chain reaction for coronavirus disease 2019: a meta-analysis. Radiology 2020;296:E145-55. [CrossRef] 